Foro, Nueva época, vol. 21, núm. 2 (2018): 465-485

ISSN:1698-5583

http://dx.doi.org/10.5209/FORO.64035

\title{
BREVE COMENTARIO A LA LEY 2/1997 DE 19 DE JUNIO, REGULADORA DE LA CLÁUSULA DE CONCIENCIA DE LOS PROFESIONALES DE LA INFORMACIÓN
}

\author{
Ildefonso SORIANO LÓPEZ \\ Sección Departamental de Derecho Constitucional \\ Facultad de Ciencias de la Información \\ Universidad Complutense de Madrid \\ isoriano@ucm.es
}

\section{RESUMEN}

Se elabora un simple y completo comentario a la Ley referida sobre la cláusula de conciencia de los profesionales de la información con referencias al Derecho comparado y a la jurisprudencia nacional española.

Palabras clave: periodistas, profesionales de la información, cláusula de conciencia, Constitución, fuentes de información, reserva, objeción.

\section{ABSTRACT}

A simple and thorough remark to such act is written on the term of Information professionals ethics linked to Compared law and to Spanish case law.

Keywords: Journalists, information professionals, ethics term, Constitution, sources of information, legal reserve, objection.

\section{ZUSSAMENFASSUNG}

Es wird eine einfache und vollständige Erläuterung zum genannten Gesetz zur Gewissensklausel der Informationsfachleute unter Bezug auf das vergleichende Recht und die nationale spanische Rechtsprechung vorgelegt.

Schlüsselwörter: Journalisten, Informationsfachleute, Gewissensklausel, Verfassung, Informationsquellen, Vorbehalt, Verweigerung.

SUMARIO: I. INTRODUCCIÓN.-II. LA CLÁUSULA DE CONCIENCIA EN EL DERECHO POSITIVO ESPAÑOL.-III. LA CLÁUSULA DE CONCIENCIA EN LOS ESTATUTOS DE REDACCIÓN DE LOS MEDIOS.-IV. LA CLÁUSULA DE CONCIENCIA EN LOS CONVENIOS COLECTIVOS DE AGENCIAS DE NOTICIAS.-V. DERECHO COMPARADO.-VI. SENTENCIAS._VII. CONCLUSIONES. 


\section{INTRODUCCIÓN}

Existen dos derechos muy importantes para los periodistas: el secreto profesional y la cláusula de conciencia. Ambos quedan recogidos en la Constitución, dentro del ámbito de los derechos fundamentales (art. 20 CE). Esto significa que hayan sido regulados, posteriormente, por leyes orgánicas o no, van a poder ser reclamados, directamente, ante los tribunales ordinarios. Y en el caso de que no fueran amparados en primera instancia por estos tribunales, podríamos reclamarlos ante el Tribunal Constitucional.

A pesar de su ubicación, muchos son los juristas que afirman que no pueden ser considerados derechos fundamentales. Aducen que son derechos instrumentales/adjetivos, de apoyo a los que realmente son sustantivos, como el derecho a la información. Consideran que la cláusula de conciencia sirve para la defensa ideológica del periodista frente a la empresa informativa y que el secreto profesional sirve para defender al periodista frente a la Administración o poder judicial al posibilitarle el no revelar la identidad de sus fuentes informativas.

Por otro lado, hay quienes los defienden como verdaderos derechos fundamentales argumentando que son sustantivos, pues con su ejercicio se garantiza la formación de una opinión pública libre, gestora del pluralismo informativo de toda democracia.

El presente artículo pretende analizar desde un punto de vista jurídico el derecho a la cláusula de conciencia reconocido en nuestra Constitución española de 1978.

Hace cuarenta años el periodista José F. Beaumont escribía: «Los grupos parlamentarios que integran la Comisión Constitucional llegaron ayer al acuerdo de incluir en el apartado d) del art. 19 (derecho de información), el reconocimiento de la cláusula de conciencia y el secreto profesional de los periodistas, cuya regulación se hará mediante ley. Culmina así - solo hay que esperar su ratificación parlamentaria- el reconocimiento legal de dos de los derechos informativos por los que más han luchado durante los últimos años, no solo los profesionales de la información españoles, sino también otros medios que exigían estos derechos como una de las garantías de la independencia informativa.

El apartado d) del art. 19 queda redactado del siguiente modo: «Los españoles tienen derecho a comunicar o recibir libremente información veraz por cualquier medio de difusión. La ley regulará el derecho a la cláu- 
sula de conciencia y al secreto profesional en el ejercicio de estas libertades.» La libertad de conciencia de los periodistas y el derecho al secreto profesional no estaban reconocidos en el texto del artículo, y fueron objeto de varias enmiendas, defendidas ayer, entre otros, por Miguel Roca Junyent (Minoría Catalana) y Luis Apostua (Unión de Centro Democrático). Los parlamentarios argumentaron, en general, que la constitucionalización de la cláusula de conciencia y del secreto profesional se presenta como un instrumento para ejercer un periodismo libre, independiente y democrático, ya que, como señaló el señor Zapatero (Grupo Socialista), «sin periodistas libres e independientes, no hay prensa libre ni independiente» ${ }^{1}$.

El derecho a la cláusula de conciencia se había reclamado en los años anteriores a la aprobación de la Constitución Española de 1978 desde diversos sectores profesionales, principalmente desde las asociaciones de la prensa. El reconocimiento de la cláusula de conciencia estaba contemplada desde hacía años en las legislaciones de la mayoría de los países europeos, aunque no en las constituciones, supone el derecho del profesional a la rescisión unilateral de su contrato que le une con la empresa en caso de modificación radical de la línea editorial del medio informativo en el que trabaja, y el derecho de este a reclamar una indemnización, como si se tratara de un despido improcedente.

Finalmente, lo encontramos dentro del título I ( De los derechos y deberes fundamentales»), capítulo II («Derechos y libertades»), Sección $1{ }^{a}$, art. 20.1.d): «Se reconoce y protege el derecho a comunicar o recibir libremente información veraz, por cualquier medio de difusión. La ley regulará el derecho a la cláusula de conciencia y al secreto profesional en el ejercicio de estas libertades». El art. 20 aparece como instrumento de protección del periodista en el ejercicio de su actividad profesional porque el derecho a la cláusula de conciencia es un instrumento jurídico, además, de ser un derecho subjetivo del periodista. Como sucede con el secreto profesional, no se trata de un privilegio o un derecho corporativo, sino que protege al periodista para conseguir una mayor transparencia informativa, que ayuda a conformar la opinión pública, elemento esencial en todo proceso participativo en un Estado de Derecho.

Según Marc Carrillo, «la cláusula de conciencia pretende salvaguardar la libertad ideológica, el derecho de opinión y la ética profesional del periodista, aspectos que, por su magnitud y trascendencia, merecen una

${ }^{1}$ J. F. Beaumont, «La "cláusula de conciencia" y el "secreto profesional" reconocidos en la Constitución», El País, 20 de mayo de 1978. 
protección especial. Así, el profesional de la comunicación podrá proceder a la rescisión de su contrato cuando el medio en el que trabaje cambie de orientación ideológica» $^{2}$.

El reconocimiento en la práctica, aunque sin el amparo de ninguna ley, de este derecho se efectuó por primera vez en España a nivel colectivo, el día 25 de febrero de 1978, a través de un pacto entre la empresa editora del Diario de Barcelona y treinta redactores del periódico, que fueron indemnizados por la empresa a raíz del cambio de director y de línea ideológica.

\section{LA CLÁUSULA DE CONCIENCIA EN EL DERECHO POSITIVO ESPAÑOL}

1. La Constitución Española de 1978: art. 20.1.d).

Como se apuntó, anteriormente, en la C. E. de 1978 aparece recogida, de la siguiente forma: «La ley regulará el derecho a la cláusula de conciencia y el secreto profesional en el ejercicio de estas libertades».

2. La norma: La Ley Orgánica 2/1997 de 19 de junio, reguladora de la Cláusula de Conciencia de los profesionales de la información ${ }^{3}$.

\section{«EXPOSICIÓN DE MOTIVOS}

La Constitución Española de 1978 ha introducido en su parte dogmática el reconocimiento del derecho de los profesionales de la información a la cláusula de conciencia. Y si bien es cierto que este derecho estaba ya reconocido por la legislación ordinaria, con diferentes grados de garantía, en diversos Estados democráticos, la aportación del texto constitucional español ha sido la de integrarlo como elemento constitutivo del derecho fundamental a recibir y comunicar información. La fuerza normativa de la Constitución ha dotado a este derecho de plena eficacia jurídica desde su promulgación y, en consecuencia, su exigibilidad jurídica vincula a poderes públicos y a particulares. Pero dicho esto, es necesario precisar su contenido, con el objeto de asegurar su correcto ejercicio por parte de los profesionales de la información como destinatarios básicos de este derecho específico y, al mismo tiempo, proporcionar a la libertad de expresión y al derecho

${ }^{2}$ M. Carrillo, La cláusula de conciencia y el secreto profesional de los periodistas: (una aproximación al estatuto jurídico de los profesionales de la información), Madrid, Civitas, 1993.

${ }^{3}$ BOE, núm. 147, de 20 de junio de 1997, pp. 19072 y 19073. 
a la información un instrumento jurídico imprescindible que garantice su ejercicio efectivo en un Estado Social y Democrático de Derecho. Esta Ley Orgánica sigue la línea trazada por el Tribunal Constitucional de instar a los poderes públicos, y, por tanto, al Parlamento a llevar a término acciones positivas en defensa de los derechos fundamentales, asegurando la imprescindible complementariedad de los valores constitucionales de libertad e igualdad. En este sentido, su articulado responde a la necesidad de otorgar a los profesionales de la información un derecho básico en la medida en que ellos son el factor fundamental en la producción de informaciones. Su trabajo está presidido por un indudable componente intelectual, que ni los poderes públicos ni las empresas de comunicación pueden olvidar. La información no puede ser objeto de consideraciones mercantilistas, ni el profesional de la información puede ser concebido como una especie de mercenario abierto a todo tipo de informaciones y noticias que son difundidas al margen del mandato constitucional de veracidad y pluralismo. En consecuencia, los elementos definidores de esta Ley Orgánica tienen un doble punto de partida: en primer lugar, la consideración del profesional de la información como agente social de la información, que ejerce su trabajo bajo el principio ineludible de la responsabilidad; y, en segundo lugar, la concepción de las empresas de comunicación como entidades que, más allá de su naturaleza jurídica —empresas públicas o privadas—, participan en el ejercicio de un Derecho constitucional, que es condición necesaria para la existencia de un régimen democrático.

Art. 1. La cláusula de conciencia es un Derecho constitucional de los profesionales de la información que tiene por objeto garantizar la independencia en el desempeño de su función profesional.

Art. 2.1. En virtud de la cláusula de conciencia los profesionales de la información tienen derecho a solicitar la rescisión de su relación jurídica con la empresa de comunicación en que trabajen: a) cuando en el medio de comunicación con el que estén vinculados laboralmente se produzca un cambio sustancial de orientación informativa o línea ideológica, b) cuando la empresa les traslade a otro medio del mismo grupo que por su género o línea suponga una ruptura patente con la orientación profesional del informador. 2. El ejercicio de este derecho dará lugar a una indemnización, que no será inferior a la pactada contractualmente o, en su defecto, a la establecida por la Ley para el despido improcedente.

Art. 3. Los profesionales de la información podrán negarse, motivadamente, a participar en la elaboración de informaciones contrarias a los principios éticos de la comunicación, sin que ello pueda suponer sanción o perjuicio.

Disposición derogatoria única. Quedan derogadas todas aquellas disposiciones que se opongan a lo establecido en la presente Ley Orgánica. 
Disposición final única. La presente Ley Orgánica entrará en vigor el día siguiente al de su publicación en el Boletín Oficial del Estado».

Como decíamos, al principio, la Cláusula de Conciencia no puede ser considerada como un derecho corporativo de los periodistas, sino como un derecho de garantía del proceso informativo en función de su transcendencia social en un Estado Social y Democrático de Derecho. Con ella se pretende conseguir la independencia del informador a la hora de desarrollar su trabajo profesional. Es por ello, que solo serán titulares de este derecho quienes participan en el proceso informativo. Nunca, otros trabajadores de los medios de comunicación que tienen otras funciones distintas de las informativas.

La Ley en su art. 1 define lo que es la Cláusula de Conciencia. Afirma, que es un Derecho constitucional de los profesionales de la información. Por tanto, deja claro quiénes van a ser los sujetos activos del derecho: los periodistas de los medios de comunicación, ya sean públicos o privados. Sin embargo, no indica lo que debemos entender por periodista. Y por periodista debemos entender, «la persona legalmente autorizada para ejercer el periodismo o la persona profesionalmente dedicada en un periódico, en un medio audiovisual o en otros similares a tareas literarias o gráficas de información y/o de creación de opinión» ${ }^{4}$.

Los medios de comunicación, con independencia de su naturaleza, siempre serán los sujetos pasivos del derecho a la cláusula de conciencia. Por tanto, la cláusula jamás podrá ser ejercida frente al informador por las empresas, ni públicas ni privadas, propietarias del medio de comunicación.

En el art. 2, la Ley exige el que haya un vínculo jurídico estable entre el informador y el sujeto pasivo, la empresa. Sin embargo, no aclara cuál ha de ser la naturaleza de la relación jurídica, ¿laboral? ¿civil o mercantil? ¿administrativa? Tampoco habla de antigüedad o dedicación. Por tanto, debemos de entender que el titular del derecho es todo periodista vinculado a la empresa de comunicación con una relación contractual laboral y que desarrolla la actividad informativa. Aquellos, que son de plantilla del medio o empresa informativa. Quedarían excluidos los que tengan otro tipo de contrato, así como los colaboradores o personas que cobran por trabajo publicado.

\footnotetext{
${ }^{4}$ Definición recogida en el Diccionario de la Real Academia de la Lengua Española.
} 
«El bien jurídico protegido por este derecho, según la Ley, es el que tiene por objeto garantizar la independencia en el desempeño de sus funciones. En conclusión, se puede manifestar que este derecho procura resguardar al periodista, ante las ideologías que posea una empresa, las cuales pueden violentar su integridad ética. Lo que se intenta es garantizar la libertad de expresión y el derecho a la información de la sociedad. El reconocimiento de la cláusula al periodista en el ejercicio de su libertad de información no puede entenderse exclusivamente como un derecho particular de aquel, sino, también, como garantía de que a través suyo se preserva igualmente la satisfacción del carácter objetivo de dicha libertad, de su papel como pieza básica en el sistema democrático y de su finalidad como derecho a transmitir y recibir una información libre y plural.

En otras palabras, la cláusula posee un fundamento ético, del cual surge el pleno respeto a la identidad del periodista en el ejercicio de su profesión. En tanto y en cuanto el periodista reconozca al público como titular del derecho a la información y a la información como un producto intelectual con función social, la cláusula de conciencia es imprescindible para garantizar la independencia de criterio del profesional en el seguimiento, obtención y tratamiento de la información. En síntesis, la cláusula de conciencia es un derecho del periodista y una garantía de la información libre y plural» ${ }^{5}$.

También, en el art. 2.1 encontramos el objeto que posibilita al informador el ejercicio del derecho. Este señala dos supuestos. En el apartado A) indica que el derecho a la Cláusula de Conciencia podrá ejercerse ante «la existencia de un cambio sustancial en la orientación informativa o en la línea ideológica del medio al que periodista está vinculado». Y, en el apartado B) en donde señala que, del mismo modo, podrá ejercerse cuando la empresa informativa «les traslade a otro medio del mismo grupo que por su género o línea suponga una ruptura patente con la orientación profesional del informador». Por tanto, el cambio en la línea editorial o en la orientación del medio ha de ser general, notable y permanente. No bastará con que el cambio haya sido solo de algún aspecto de la información. Y, en el segundo supuesto, no se han de demostrar las razones de conciencia. Lo que se está protegiendo son las condiciones laborales. Y, habrá de constatarse que el traslado del periodista para trabajar en otro medio supone una ruptura con el trabajo anteriormente desarrollado. Ha quedado claro, en numerosas ocasiones, que el titular de la empresa periodística ha utilizado el traslado para limitar el ejercicio «incómodo» del profesional.

5 M. C. GÜIDA, «La cláusula de conciencia: un derecho para el periodista», Derecho y Comunicación 2.0., junio de 2010. 
Por último en el art. 2.2, nos habla del efecto a que da lugar su ejercicio. El efecto, no es ni más ni menos que la extinción del contrato laboral y al pago de una indemnización. Por tanto, por un lado, se produce la rescisión del contrato laboral de forma unilateral. La provoca el periodista. Este es quien decide abandonar voluntariamente su puesto de trabajo. Y, por otro lado, la empresa titular del medio informativo es la que debe hacer frente a la indemnización al profesional que invocó la Cláusula de Conciencia. La cuantía de la indemnización podría estar recogida en el contrato laboral, si en su momento se pensó en esta posibilidad. O, también, podría acordarse en un pacto cuando se produjese esta situación. En caso de que no hubiese sido prevista, ni se llegase a un acuerdo pactado, la cantidad sería aquella que le correspondiese el profesional, por despido improcedente, distinto del abandono voluntario y despido procedente. Si el empresario se negase a satisfacer la misma, el periodista podría acudir a los tribunales para reclamarla judicialmente. En el contenido, tampoco, encontramos que la ley exija un plazo perentorio para poder ejercer el derecho. Por ello, debemos de interpretar que se podría ejercer en un periodo de tiempo razonable desde que se produjeron las modificaciones en la línea ideológica del medio. Como ya se ha apuntado anteriormente, el profesional de la información debe probar que las mismas, no son solo percepciones propias.

En el art. 3 se reconoce el derecho del periodista a poder negarse a elaborar informaciones contrarias a los principios éticos de la comunicación. Los profesionales de la información deberán realizar el trabajo que le encomienden sus directores o jefes de redacción y los propietarios del medio. Sin embargo, estos podrán negarse, sin recibir sanción o perjuicio alguno, cuando se demuestre que la negativa se basa en razones ideológicas o éticas. De esta forma, sería una especie de «objeción de conciencia ideológica», como señala el profesor Niceto Blázquez. Del mismo modo, se pronuncia en un comentario a la ley el, también, profesor Rafael Díaz que es partidario de haber denominado la misma como «la cláusula y objeción de conciencia», ya que la ley defiende el derecho del profesional a negarse a actuar en contra de los principios éticos de la comunicación sin llegar hasta el extremo de querer rescindir el contrato de trabajo ${ }^{6}$.

Después de más de veintiún años de su aprobación, numerosos estudiosos de la ley, coinciden en que son muchas las carencias de la misma.

${ }^{6}$ R. Díaz Arias, «La cláusula de conciencia» en I. BeL y L. Corredorra (dirs.), Derecho a la Información, Barcelona, Ariel, 2013, pp. 327-345. 


\section{LAS CLÁUSULAS DE CONCIENCIA EN LOS ESTATUTOS DE REDACCIÓN DE LOS MEDIOS}

Los Estatutos de Redacción son expresamente recomendados por la Asamblea Parlamentaria del Consejo de Europa en su resolución 1003 sobre Ética del Periodismo, aprobado el 1 de julio de 1993, como instrumento de ordenación de las relaciones profesionales de los periodistas con los propietarios y editores, con independencia de las obligaciones laborales ${ }^{7}$.

Antes y después de la aprobación de la ley algunos medios de comunicación, recogen la Cláusula de Conciencia en sus estatutos de redacción. Este derecho se refleja en los estatutos de diferente modo. Blanco Jover distingue entre los estatutos «de primera generación», aprobados antes de la LO 2/1997 y los de «segunda generación», que reproducen de manera más o menos ampliada el contenido de la norma legal de referencia ${ }^{8}$.

En este sentido cabe citar, por ser uno de los periódicos más importantes e influyentes españoles, el de El País ${ }^{9}$. El rotativo indica varios supuestos en los que sus profesionales ${ }^{10}$ podrán invocar el derecho a la Cláusula de Conciencia:

«1. El cambio sustancial de la línea ideológica de El País, puesto de manifiesto por actos reiterados, será motivo para que el miembro de la redacción que se considere afectado en su libertad, honor o independencia profesional pueda, sin preaviso, invocar cláusula de conciencia y, en su caso, dar por resuelto o extinguida su relación laboral ${ }^{11}$. Prácticamente, coincide con lo que se señala en el art. 2.1.A) de la Ley.

7 «Within the newspaper business, publishers, proprietors and journalists must live side by side. To that end, rules must be drawn up for editorial staff in order to regulate professional relations between the journalists and the publishers and proprietors within the media, separately from the normal requirements of labour relations. Such rules might provide for the setting up of editorial boards» (clause 32). CE, Parliamentary Assembly, Resolution 1003 (1993) on the Ethics of Journalism, recuperado de http://assembly.coe.int/Main.asp?link=/Documents/ AdoptedText/ta93/ERES1003.htm.

${ }^{8}$ C. Blasco Jover, El derecho a la cláusula de conciencia de los profesionales de la información, Albacete, Bomarzo, 2009. p. 136.

${ }^{9}$ El Estatuto de la Redacción de El País fue aprobado el día 20 de junio de 1980 por la junta general de accionistas de Promotora de Informaciones, S. A. (PRISA).

${ }^{10}$ En el art. 2 se señala quiénes son los miembros de la redacción: «Todos los periodistas, al margen de la titulación que posean, que realicen tareas de redacción, adscritos a su plantilla, al menos con seis meses de antigüedad».

${ }^{11}$ Art. 5 del Estatuto de la Redacción de El País. 
2. Igualmente podrá alegarse la cláusula de conciencia, con los efectos jurídicos de ella derivados regulados en los párrafos anteriores, cuando a algún miembro de la redacción se le imponga la realización de algún trabajo que él mismo considere que vulnera los principios ideológicos y violenta su conciencia profesional ${ }^{12}$. Se asemeja mucho al contenido del art. 3 .

3. Ningún miembro de la redacción estará obligado a firmar aquellos trabajos que, habiéndole sido encomendados o que, realizados por propia iniciativa, hayan sufrido alteraciones de fondo que no sean resultado de un acuerdo previo. Las normas de estilo no podrán ser fundamento para invocar la cláusula de conciencia. Ni dichas normas de estilo ni las modificaciones en los sistemas de trabajo podrán alterar el contenido de este estatuto ${ }^{13} \gg$.

Del mismo modo, podríamos citar el de $E l$ Mundo $^{14}$, que dice:

Si la línea editorial de El Mundo se apartara sustancialmente de los principios ideológicos recogidos en este estatuto, los periodistas podrán alegar este hecho como causa suficiente para la rescisión unilateral del contrato. Para que se pueda alegar cláusula de conciencia debe producirse alguno de los siguientes supuestos:

1. Que el miembro de la redacción resulte afectado en su libertad, dignidad o independencia profesional, como consecuencia de la modificación de los principios ideológicos.

2. Que se ponga de manifiesto, a través de actos reiterados, una modificación en el contenido editorial del periódico y/o de su línea ideológica, bien como consecuencia de una modificación significativa de la titularidad del capital de la empresa, o de cualquier otra circunstancia.

Procedimiento

En los casos en los que se alegue cláusula de conciencia el consejo de redacción actuará como mediador entre la empresa y el redactor afectado. Si no se llega a un acuerdo satisfactorio para ambas partes, el conflicto podrá ser planteado ante los tribunales de justicia ${ }^{15}$.

Posterior, a la Ley, se aprobó el Estatuto de Información de la Corporación $\mathrm{RTVE}^{16}$ :

12 Art. 5 del Estatuto de la Redacción de El País.

${ }_{13}$ Art. 6 del Estatuto de la Redacción de El País.

14 El Estatuto de la Redacción de El Mundo fue aprobado en 1990.

15 Art. 6 del Estatuto de la Redacción de El Mundo.

${ }^{16}$ El Estatuto de Información de la Corporación RTVE fue aprobado en 2008. 
«Art. 13. Los profesionales de la información audiovisual, sea cual fuere su adscripción orgánica, podrán ejercitar la cláusula de conciencia en los términos establecidos en la Ley Orgánica 2/1997. Este derecho podrá ejercerse teniendo en cuenta que en la Corporación RTVE la línea editorial viene determinada por la Ley 17/2006, el mandato marco aprobado por las Cortes Generales y los Principios Básicos de la Programación aprobados por el Consejo de Administración.

Art. 14. A petición de los profesionales que invoquen la cláusula de conciencia, los respectivos consejos de informativos mediarán ante la dirección correspondiente. En ningún caso la intervención de los consejos se considerará requisito previo para el ejercicio de este derecho.

Art. 15. Conforme a lo dispuesto en la Ley Orgánica 2/1997, los profesionales de la información audiovisual podrán negarse motivadamente a participar en la elaboración y difusión de informaciones contrarias a los principios éticos y deontológicos de la comunicación, especialmente a los enunciados en este Estatuto o a los principios editoriales definidos en el mandato-marco, sin que esta negativa comporte ningún tipo de sanción ni perjuicio laboral.

Art. 16. Los profesionales de la información audiovisual podrán invocar la anterior facultad en el desempeño normal de su trabajo. Si no fuera posible eximirles de esa tarea sin paralizar la cobertura informativa, cumplirán el encargo sin que puedan ser obligados a firmar, leer o aparecer en imagen.

Art. 17. El autor de la información, sea cual sea su adscripción orgánica, podrá retirar su firma o negarse a leer o presentar en imagen una información cuando esta, en el proceso de control editorial o de reelaboración, reemisión o reutilización en otra plataforma o soporte de difusión, resulte sustancialmente modificada en su sentido o forma. El ejercicio de esta facultad no dará lugar a sanción o perjuicio profesional.

Art. 18. La cláusula de conciencia no podrá ser invocada por los profesionales de la información adscritos a los programas de derecho de acceso».

En resumen, como señalan los profesores universitarios Carmen Fuente y José Alberto García ${ }^{17}$, los derechos habitualmente reflejados en los estatutos de redacción son los siguientes:

- Derecho de un redactor a solicitar la rescisión de su contrato obteniendo una indemnización, si se produce un desvío constatable y permanente en la línea ideológica del medio.

17 C. Fuente y J. García, «La aplicación de la cláusula de conciencia de los periodistas en España». Cuadernos Info, núm. 35 (2014). 
- Derecho de un redactor a negarse a la realización de un trabajo que suponga vulnerar los principios fundacionales del medio.

- Derecho de un redactor a negarse a la realización de un trabajo que implique la vulneración de principios de ética profesional.

- Derecho de un redactor a negarse a la realización de un trabajo si considera que se violenta su conciencia o convicciones personales.

- Derecho de un redactor a retirar su firma (o a no aparecer en pantalla) de informaciones que considere que han sido alteradas sustancialmente sin su consentimiento.

- Derecho de la redacción a exponer su discrepancia a través del propio medio, si por mayoría de la misma (habitualmente de dos tercios) considera que dicho medio ha violado sus principios fundacionales o los principios de la ética periodística.

\section{LA CLÁUSULA DE CONCIENCIA EN LOS CONVENIOS COLECTIVOS DE AGENCIAS DE NOTICIAS}

En este escenario de desactivación profesional son muy importantes los sindicatos. No en vano, los sindicatos son las únicas organizaciones reconocidas legalmente para representar y negociar, en nombre de los trabajadores, sus condiciones laborales. No obstante, en un análisis realizado por los mismos profesores, sobre cerca de treinta convenios colectivos en el sector de empresas de medios informativos suscritos entre 1996 y 2013 y que afectan a empresas informativas de ámbito estatal o cuya actividad afecta a más de una comunidad autonómica, se desprende que son muy escasos los textos que recogen el derecho a la cláusula de conciencia de los periodistas ${ }^{18}$.

El primer convenio estatal de prensa diaria, aprobado en el año 2000, instaba a las empresas del sector a poner en marcha estatutos de redacción. Esta reclamación se ha mantenido en los dos convenios posteriores, incluido el actualmente en vigor. En el sector de prensa no diaria (revistas), en 2008 se suprimió el artículo dedicado a la cláusula de conciencia, que había sido incluido en el primer convenio del sector, suscrito en 1996. Los únicos textos en los que se encuentra expresamente recogida la cláusula de conciencia son los convenios colectivos de las agencias de noticias Europa Press y Servimedia, así como en los de la Agencia estatal EFE y de la privada Colpisa, si bien en estos dos últimos casos se encuentra formula-

${ }^{18}$ Ibid. 
do en relación con los derechos de los periodistas sobre su firma. Así pues, vemos que la cláusula de conciencia no aparece como una reivindicación significativa en la agenda de las negociaciones colectivas salvo en el notable caso de las agencias de noticias, ya que todas ellas cuentan con convenios particulares que abordan, de una u otra manera, el derecho de los redactores a negarse a realizar $-\mathrm{O}$ a firmar-, informaciones que vayan contra sus principios morales o ideológicos ${ }^{19}$.

Veamos el contenido de algunos de los Convenios Colectivos citados:

1. Europa Press: «La Dirección de la Empresa no podrá obligar a su personal a elaborar, para su publicación aquellas informaciones que vayan contra sus principios morales o ideológicos» $\left(\right.$ art. 13 ${ }^{20}$.

2. Servimedia: «La dirección de la empresa no podrá obligar a su personal a realizar aquella información que vaya en contra de sus principios morales o ideológicos. Cuando por necesidades haya que elaborar una información que sea objeto de invocación de la cláusula de conciencia por parte de un/a trabajador/a, la responsabilidad de su difusión será de aquel que la ordene. La invocación de la cláusula de conciencia o del secreto profesional nunca será motivo de traslado, sanción o despido del profesional que se acoja a este derecho» (art. 12) ${ }^{21}$.

3. EFE: «La Empresa no podrá obligar a su personal a firmar aquellas informaciones que vayan en contra de sus principios morales o ideológicos. Cuando, por razones de urgencia, un trabajador haya de elaborar una información que pueda ser objeto de invocación de esta cláusula, la responsabilidad será de aquel que lo ordene» $(\operatorname{art} .32 .2)^{22}$.

4. Colpisa: «En el supuesto de que cualquier creación fuera modificada en su contenido o extensión, el Autor de la misma tendrá derecho a que se elimine su firma al pie del artículo o reportaje de que se trate» (art. 26) ${ }^{23}$.

19 Ibid.

${ }^{20}$ Resolución de 10 de diciembre de 2009, de la Dirección General de Trabajo, sobre registro, depósito y publicación del convenio colectivo de la empresa Europa Press Noticias, Sociedad Anónima (Boletín Oficial de la Comunidad de Madrid, núm. 62, de 15 de marzo de 2010).

${ }^{21}$ Resolución de 7 de abril de 2010, de la Dirección General de Trabajo, sobre registro, depósito y publicación del convenio colectivo de la empresa Servimedia, Sociedad Anónima (Boletín Oficial de la Comunidad de Madrid, núm. 139, de 12 de junio de 2010).

${ }^{22}$ Resolución de 1 de octubre de 2010, de la Dirección General de Trabajo, por la que se registra y publica el Convenio colectivo de Agencia Efe, S. A. (Boletín Oficial del Estado, núm. 250, de 15 de octubre de 2010).

${ }^{23}$ Resolución de 10 de octubre de 2011, de la Dirección General de Trabajo, sobre 


\section{DERECHO COMPARADO}

\section{Austria}

La Ley de 12 de junio de 1981 comprende la cláusula de conciencia como un conjunto de facultades frente al poder directivo del empresario de comunicación y no como una forma para extinguir la relación laboral. Así se manifiesta en algunos de sus artículos: art. 2 reconoce el derecho a) «negarse a confeccionar noticias o programas que sean contrarios a las convicciones del periodista en cuestiones fundamentales o a los principios del periodismo sin que ello suponga sanción o perjuicio». El art. 3 reconoce el derecho a) «impedir la publicación de un artículo si este ha sido modificado sin autorización del autor».

\section{Francia}

En 1935 se aprobó la Ley Brochard, también conocida como Estatuto del Periodista Profesional. Este texto define por primera vez lo que es un periodista, ${ }^{24}$ a los que declara trabajadores por cuenta ajena, con todo lo que esto conlleva en el ámbito de la legislación laboral. Y, también se reconoce a todo aquel que sea titular de un carné de prensa la cláusula de conciencia y el derecho a percibir un mes de salario por año trabajado en caso de despido. El Código de Trabajo reformado por última vez en 2008 en la Sección II, dice sobre la Rescisión del contrato laboral, art. L. 761-7: Las disposiciones del art. L. 761-5 (acerca de indemnización por despido) se aplican en el caso en el que la rescisión del contrato provenga de alguien empleado en una empresa periodística mencionada en el art. L. 761-2, cuando esta rescisión esté motivada por una de las circunstancias siguientes: 1) transferencia del diario o de la publicación; 2) cese del diario o de la publicación, por cualquier causa; 3) cambio significativo en el carácter u orientación del diario o publicación, si este supone para el periodista una

registro, depósito y publicación del convenio colectivo de la empresa «gencia Colpisa, Sociedad Limitada Unipersonal (Boletín Oficial de la Comunidad de Madrid, núm. 281, de 26 de noviembre de 2011).

${ }^{24}$ La profesión de periodista está definida legalmente por la Ley Brachard de 29 de marzo de 1935 (art. L. 761-2 del Código del Trabajo), modificada por la Ley Cressard de 4 de julio de 1974 (núm. 74-630).

Considera como periodista «aquel que por ocupación principal, regular y retribuida ejerce su profesión en una o varias publicaciones cotidianas o periódicas, o en una o varias agencias de prensa y de las que obtiene la mayor parte de sus recursos». 
situación que atente contra su honor, a su fama o, en general, a sus intereses económicos. En el caso previsto en el núm. 3, la persona que rompe el contrato no está obligada a observar el tiempo de preaviso previsto en el art. L. 761-4.

\begin{abstract}
Alemania
La cláusula de conciencia no se ha regulado por ley. Sin embargo, sí que se encuentra reconocida en numerosos convenios colectivos de los medios de comunicación. Estos obligan a incluir en el contrato individual una declaración sobre la tendencia del periódico. Y, en el caso de que la línea editorial del medio cambie, el profesional de la información podrá poner fin a su contrato, en un mes por motivos de conciencia. La indemnización es, aproximadamente, de seis meses de su salario. En el caso de que el medio cambie de propietario, los contratos de trabajo del personal pasan a la nueva empresa.
\end{abstract}

\title{
Bélgica
}

Tampoco existe ley que regule la cláusula de conciencia y, del mismo modo, forma parte de algunos convenios colectivos, como los de prensa diaria y el de prensa no diaria.

\section{Portugal}

La cláusula de conciencia fue reconocida en la Ley de Prensa de 24 de febrero de 1975. Fruto de ella es la creación del «Conselho de Imprensa», que comienza sus actividades en mayo del mismo año, institución independiente en la que está representado todo el sector, trabajadores, empresarios y administración, incluso lectores, como órgano arbitral que va desarrollar una intensa labor en estos años de permanente tensión política. Al Conselho se le encomienda el control de las tiradas de todas las publicaciones, pero, dada la precariedad de sus medios, no conseguirá un control efectivo ${ }^{25}$. Si se lleva a cabo una alteración profunda en la línea de orientación del periódico, confirmada por el Consejo de Imprenta, los periodistas podrán extinguir la relación laboral por su iniciativa y tienen

25 A. CheCA Godoy, «Del clavel al euro. 25 años de prensa en Portugal», Revista Latina de Comunicación Social, núm. 26 (2000), disponible en http://www.ull.es/publicaciones/ latinalaa2000vfe/checa.html. 
derecho a la indemnización debida por despido injustificado o sin previo aviso.

\section{Italia}

En el ordenamiento jurídico italiano, la cláusula de conciencia quedó regulada mediante Contrato Colectivo de Negociación (Contrato Nazionale di Lavoro Giornalistico), firmado en su último texto este mismo año. Limita su ejercicio a aquellos profesionales que intervengan en tareas que comporten un exclusivo contenido político, bien de dirección, de redacción, de análisis, etc. Posteriormente se amplió a todas las funciones que puedan desarrollar las empresas periodísticas. De este modo, podrán invocarlo los redactores que intervengan en crónicas de cine, de teatro o en críticas literarias.

\section{Chile}

Ley sobre las libertades de opinión e información y ejercicio del periodismo de 2001 indica en su art. 8: «El periodista o quien ejerza la actividad periodística no podrá ser obligado a actuar en contravención a las normas éticas generalmente aceptadas para el ejercicio de su profesión».

\section{Paraguay}

La Constitución Nacional, que data de 1992, indica en su art. 29: «Los periodistas de los medios masivos de comunicación social, en cumplimiento de sus funciones, no serán obligados a actuar contra los dictados de su conciencia».

\section{Bolivia}

La Constitución Política del Estado de Bolivia de 2009 la reconoce en el art. 106-IV donde señala que «se reconoce la cláusula de conciencia de los trabajadores de la información». El art. 14 del Decreto Supremo 20225, de 9 de mayo de 1984, ya indicaba que «ningún periodista podrá ser despedido por sus ideas o creencias, sean estas políticas, religiosas o sindicales». El periodista puede expresar posiciones contrarias a las de su empleador en el campo político, religioso o sindical. La norma que clarifica la cláusula de conciencia está en el art. 15, cuando manda «Establécese la Cláusula de conciencia, entendiéndose por tal el derecho de un periodista de separarse voluntariamente de la empresa cuando se produzca 
un cambio de orientación ideológica que le implique un conflicto conciencial». En el art. 16, sostiene que «el retiro de un periodista de su empresa apoyada en la cláusula de conciencia, le da derecho de indemnización conforme a ley. Si hubiera divergencia sobre la aplicabilidad de tal cláusula al caso, las partes recurrirán al Tribunal de Honor de la Prensa, que fallará en única instancia».

\section{SENTENCIAS}

Hay que comenzar afirmando que la jurisprudencia sobre esta materia es muy escasa e incluso, en la mayoría de la veces, indirecta. Pues no se invoca la ley objeto del estudio, sino la genérica violación del derecho a la libertad de expresión o información.

A continuación vamos a analizar la sentencia de Tribunal Constitucional núm. 199/99, de 8 de noviembre. Los hechos fueron los siguientes A. D. L. trabajaba como jefe de la sección de diseño de Diario 16 desde 1982. El periódico había nacido como un medio de comunicación centrado en el mundo obrero. Sin embargo, según A. D. L., a partir de 1989 ese tipo de información se vio disminuida en favor de la de tipo financiero. Por ello, el trabajador consideró estar en desacuerdo con esa nueva línea de tratamiento de la información y que atentaba contra su ideología e invocó la cláusula de conciencia y solicitó la correspondiente indemnización.

Una vez interpuesta la demanda, se celebró el juicio en 1994 que le dio la razón al periódico. Ante lo cual, el trabajador interpuso un recurso de suplicación ante el Tribunal Superior de Justicia de Andalucía, que también falló en su contra. Para ello, los tribunales se basaron en que A. D. L. no era redactor, ni periodista, por lo que un cambio de ideología del diario no le obligaba a escribir en contra de la propia. Y, también, que el aumento de un tipo de información no significaba un cambio notable de la línea editorial del periódico.

Más tarde, el trabajador interpuso un recurso de amparo ante el Tribunal Constitucional para poder recibir la indemnización deseada al abandonar el diario. Sin embargo, la misma también fue denegada. En las alegaciones a la resolución, la defensa del trabajador argumentó que su cliente tenía derecho a invocar la Cláusula de Conciencia y que la idea del cambio ideológico del diario dependía de una valoración subjetiva.

Una vez admitida a trámite la demanda de amparo se exigió también el testimonio de los tribunales implicados y en septiembre de 1999 se decidió 
dar vista a las alegaciones que habían sido presentadas. Sin embargo, finalmente, el fallo de TC fue desestimatorio.

La defensa del diario argumentó que el rotativo tenía una ideología objetiva e independiente desde su creación en el 1976 pero que, tras la creación del periódico «El Mundo su espacio dedicado a la información bursátil y financiera aumentó gracias a la dedicada al mundo laboral desde 1989.

Considero acertada la resolución del Tribunal Constitucional por las siguientes razones: no cualquier trabajador de un medio de comunicación puede invocar la Cláusula de Conciencia del art. 20.1 de la CE de 1978. Es un derecho, solo de los periodistas. La ley no identifica quien es el profesional de la información, a efectos de la cláusula de conciencia, aunque deja claro que debe existir un vínculo laboral.

La Sentencia indica: «El derecho a la cláusula de conciencia encuentra, pues, su ámbito subjetivo de aplicación en las relaciones contractuales de los profesionales de la información con las empresas de comunicación para las que trabajan, con vistas a la garantía del ejercicio de su propia libertad informativa. La afectación del derecho de información del profesional como criterio de legitimación para la invocación de la cláusula impide en términos constitucionales la elaboración de un catálogo cerrado de funciones cuyos titulares pudieran reclamarla; máxime teniendo en cuenta la variedad de tareas en las que la libertad informativa puede verse involucrada en una sociedad en la que en la transmisión de noticias no juegan un papel esencial solo las palabras, sino tanto o más las imágenes, fotografías, presentaciones gráficas o de composición que contribuyen igualmente a la descripción del hecho, a destacar ciertos aspectos de él, a lograr un enfoque ideológico determinado o a dotarle de una mayor o menor relevancia informativa según los intereses del medio, tareas todas ellas en las que además habrá de considerarse la autonomía y creatividad propias con las que opere el profesional para poder concluir que se encuentra ejerciendo su derecho a transmitir información. En definitiva, como afirma el Ministerio Fiscal, la delimitación subjetiva del derecho no puede hacerse con abstracción de las funciones realizadas, como tampoco limitarse indebidamente a determinadas categorías profesionales excluyendo otras potencialmente susceptibles de ser integradas en la regulación de la cláusula» ${ }^{26}$. Además de todo lo anterior, se debe añadir:

${ }^{26}$ Sentencia de la Sala Segunda del Tribunal Constitucional 199/1999, de 8 de noviembre de 1999 (BOE, núm. 300, de 16 de diciembre de 1999, pp. 3-9). 
1. El propio convenio colectivo del trabajador señalaba que esta, solo puede ser invocada por periodistas.

2. El trabajador quiso ampararse en la Constitución Francesa que extiende la Cláusula de Conciencia a otros trabajadores del medio de comunicación. Pero resulta muy cierto que su trabajo en el rotativo, en la sección de confección y diseño, nada tiene que ver con la labor periodística.

3. La Sentencia considera como criterio relevante para identificar una posible vulneración del derecho a la Cláusula de Conciencia el hecho de que la restricción impuesta al trabajador afecte a «la transmisión de información relevante para la formación de la opinión pública», pero no la incidencia que pudiera tener en sus convicciones personales de manera independiente ni sobre su autonomía ${ }^{27}$.

4. El trabajador no tiene derecho a invocar la Cláusula de Conciencia y, por tanto, a recibir la indemnización, ni aunque hubiese sido cierto el cambio notable de la ideología del diario. De ahí el fallo desestimatorio.

Otra Sentencia de invocación directa es la STC 225/2002, de 9 de diciembre, que conoce el recurso de amparo de un profesional de la información que pone fin a su relación laboral con la empresa informativa como consecuencia de un cambio ideológico del medio en el que trabaja. Las anteriores sentencias de la instancia y de la Sala del Tribunal Superior de Justicia desestimaron su pretensión pese a que quedó demostrado el cambio ideológico, porque el periodista dejó de trabajar en el momento que sus abogados interpusieron la demanda, y la empresa alegó abandono del puesto de trabajo. El Tribunal Constitucional estimó el recurso de amparo razonando, igual que el Ministerio Fiscal, que desde que se produce el cambio de la línea editorial, la continuidad en el puesto de trabajo, implicaba una apariencia engañosa para las personas que recibían esa información, y que si resultaba probado el supuesto del art. 2 de la Ley no puede imponerse al periodista que durante la tramitación procesal tenga que permanecer en la empresa ${ }^{28}$.

El fallo fue:

1. Reconocer su derecho a la cláusula de conciencia [art. 20.1.d) CE].

2. Declarar la nulidad de la Sentencia de la Sala de lo Social del Tribunal Superior de Justicia de Madrid de 5 de mayo de 1998, dictada en recurso de suplicación núm. 1729/98, y de la Sentencia del Juzgado de

27 STC 199/1999, de 8 de noviembre, FJ 5. ${ }^{\circ}$

28 Sentencia de la Sala Primera del Tribunal Constitucional 225/2002, de 9 de diciembre de 2002 (BOE, núm. 9, suplemento, de 10 de enero de 2003, pp. 4-8). 
lo Social núm. 22 de Madrid de 24 de diciembre de 1997, dictada en autos 697/97.

3. Retrotraer las actuaciones procesales al momento inmediatamente anterior a la Sentencia de 24 de diciembre de 1997, a fin de que se dicte nueva resolución con respeto al derecho fundamental reconocido ${ }^{29}$.

Otra, de invocación indirecta es la STC 125/2007, de 21 de mayo resuelve el recurso de amparo, promovido por el periodista Francisco Frechoso Bajodo al que su empresa Unidad Editorial, S. A., que es editora del periódico El Mundo, le deniega autorización para poder seguir participando en una tertulia televisiva. El recurrente prestaba sus servicios en dicho medio desde su fundación, primero como corresponsal político y después como redactor jefe (en el momento de la demanda, redactor jefe de cierre). El periodista había denunciado en la tertulia que su periódico obstaculizaba el derecho de huelga de sus trabajadores. En la demanda lo que se alegaba era la violación del derecho a la libertad de expresión y a la igualdad, en la medida en que la empresa había adoptado tal medida como represalia por el uso de su libertad de expresión, y así lo resuelve el TC. En realidad, en este caso podría operar la consideración de la cláusula de conciencia, si la legislación acerca de esta no se hubiese limitado a la posibilidad de resolución de contrato, y se hubiera regulado la situación del trabajador que la invocaba sin necesidad de producir la ruptura del vínculo laboral ${ }^{30}$.

\section{CONCLUSIONES}

1. A pesar de ser un derecho reconocido en nuestra CE de 1978 y en la ley reguladora de 1997, ha sido invocado escasamente por periodistas ante los tribunales de justicia españoles. Quizá, si existiese en nuestro país un Estatuto Jurídico de la Profesión Periodística, en donde quedasen claramente delimitados los derechos y deberes de los profesionales de la información, se habría recurrido a ella, en mayor número de ocasiones.

2. La ausencia de esa norma específica hace que se tenga que aplicar la legislación laboral común. Y facilita un mayor control por parte de la empresa, de los profesionales de la información que realzan su trabajo, a través del director del medio. Por ello, la autonomía de los periodistas en

${ }^{29}$ Ibid.

30 Sentencia de la Sala Primera del Tribunal Constitucional 125/2007, de 21 de mayo de 2007 (BOE, núm. 149, suplemento, de 22 de junio de 2007, pp. 49-56). 
las redacciones, es escasa. Se impone, la obligación de tratar un tema en un determinado sentido. A pesar de que el periodista está protegido por la ley de la cláusula de conciencia casi no se usa.

3. El derecho de veto del director sobre el trabajo del periodista está aceptado y normalizado. Contra el cual no existe recurso jurídico. Este puede eclipsar la cláusula de conciencia.

4. Del mismo modo, está, generalmente, aceptado que la empresa altere o corrija la obra periodística.

5. No existen asociaciones $\mathrm{u}$ organizaciones profesionales suficientemente fuertes que representen al colectivo periodístico y que tutelen sus derechos.

6. Tampoco los sindicatos mayoritarios y adonde están afiliados más periodistas, representan adecuadamente los derechos profesionales y laborales de aquellos.

7. Por último, la crisis económica que atraviesa el sector de los medios de comunicación ayuda a que no se respeten, mínimamente, los derechos de los profesionales de la información. 